\title{
A METHOD OF ESTIMATING PROBABILISTIC SEISMIC LOAD FOR SHORT DURATIONS
}

\author{
By Yozo YUI*, Susumu HIROSE** and Eiichi KURIBAYASHI***
}

\begin{abstract}
This paper presents the use of the past seismic data to predict seismic motion intensity for short duration. The factors that affect this predicted value are studied, and application to a selected site of the straits of Akashi is presented. The study using a areal source model with assumed seismicity in each divided zone showed that earthquake of relatively small magnitude in the site plays an important role for estimating expected seismic load of the site. For structures under construction, an attempt to estimate the expected value of restoration cost for a three-span suspension bridge by probabilistic approach is also presented.

Keywords : seismic risk analysis, short duration, suspension bridge, restoration cost
\end{abstract}

\section{INTRODUCTION}

For design purposes, it is necessary to assess properly the expected intensity of seismic motions for sites where structures are to be constructed. The seismic motion intensity varies from site to site depending on the surrounding state of seismic occurrence. For this, the existing specifications for earthquake-resistant design use a modified method with regional correction factor to derive the seismic intensity for design ${ }^{1)}$. However, it has become necessary to estimate a detailed seismic motion intensity based on the level of seismic activities at the surrounding area of a site for designing long span bridges. For this reason, the seismic motion intensity with some degree of accuracy has so far been predicted on the past seismic records ${ }^{2)}$. An expected value of the seismic motion intensity obtained contains many unclear factors, and these factors may become the cause of variation in predicted values of seismic motion intensity ${ }^{3), 4)}$.

The construction of long span bridges has a tendency for prolonged construction period. These structures in some cases are not in stable conditions while being constructed as compared to those in service. In general, the seismic motion intensity is smaller during the construction period compared to that after completion, and depending on the earthquake-resistant design under construction, the risk of damage exists. This can possibly be reduced on site experiences, or by the technical ingenuity of the personnel responsible for the construction technique, although it is difficult to reduce the risk to zero. This kind of seismic loads for relatively short durations has not been clarified by the existing specifications for earthquake-resistant design, thus, it is necessary to have a proper predicting method for this purpose $\mathrm{e}^{4)-6)}$.

\footnotetext{
* Member of JSCE, M. Eng., Tokyo Engineering Co., Ltd. (Hatchobori, 4-chome, Chuo-ku, Tokyo).

** Member of JSCE, M. Eng., Toyohashi University of Technology (Tempaku-cho, Toyohashi).

*** Member of JSCE, Dr. Eng., Professor, Toyohashi University of Technology (Tempaku-cho, Toyohashi).
} 
This study presents a probabilistic evaluation method for seismic motion intensity in relatively short durations. The factors that affect the seismic motion intensity of the short durations are evaluated and an application of the evaluation method to the installation models of a long-span suspension bridge is presented by using the probabilistic approach, in which initial construction costs, the probability of failure by seismic motion intensity and restoration costs are taken account of.

\section{PREDICTING METHOD FOR SEISMIC LOAD ${ }^{10}$}

\section{(1) State of seismic activity of source region}

The relation for the magnitude and frequency of occurrence of past earthquakes is represented by Gutenberg-Richter formula, hereafter called G-R Formula, is as follows ;

$\log n(m)=a-b \cdot m$

where $n(m) \cdot d m$ is the frequency of the seismic occurrence between magnitude $m$ and $m+d m$. The maximum magnitude of earthquakes may be taken as a parameter $m_{u}$, and Eq. (1) may be modified as follows ${ }^{8)}$;

$$
\left.\begin{array}{rlrl}
\log n(m) & =a-b \cdot m & & \left(m \leqq m_{u}\right) \\
n(m) & =0 & & \left(m>m_{u}\right)
\end{array}\right\}
$$

and,

$$
\left.\begin{array}{rlrl}
\log n(m) & =a-b \cdot m+\log \left(m_{u}-m\right) & & \left(m<m_{u}\right) \\
n(m) & =0 & & \left(m \geqq m_{u}\right)
\end{array}\right\}
$$

Eq. (2) and Eq. (3) are generally called the truncated G-R formula and the modified G-R formula respectively. For using Eq. (2) and Eq. (3), the cumulative density functions $F_{M}(m)$, respectively are as follows;

$$
F_{M}(m)=\frac{1-\exp \left\{-\beta\left(m-m_{0}\right)\right\}}{1-\exp \left\{-\beta\left(m_{u}-m_{0}\right)\right\}}
$$

and

$$
F_{M}(m)=\frac{1-\left\{1-\beta\left(m_{u}-m\right)\left\{\exp \left\{-\beta\left(m-m_{0}\right)\right\}-\beta\left(m_{u}-m_{0}\right)\right.\right.}{1-\exp \left\{-\beta\left(m_{u}-m_{0}\right)\right\}-\beta\left(m_{u}-m_{0}\right)} .
$$

where $\beta=b \cdot \ln 10$, and $m_{0}$ is the minimum magnitude to be used for analysis.

\section{(2) Attenuation property of seismic motion}

The attenuation property of seismic motions is required for predicting seismic motion intensities at a site based on the state of the seismic activities in the source region. To this, the attenuation formula proposed in reference 9) is adopted as follows;

$$
\bar{y}=f(m, r)=A \cdot 10^{B \cdot m} \cdot\left(r+r_{0}\right)^{c}
$$

where $\bar{y}$ is the expected value of seismic motion intensity used for analysis, $\mathrm{r}$ is the distance from epicenter and $A, B, C, r_{0}$ are parameters. When the parameters $A, B$, and $C$ are determined from multiple regression analysis by using past seismic data, dispersion exists between the predicting formula and the measured values. The index of the dispersion is defined as a ratio $U=y_{0 b} / \bar{y}$, of measured value and predicted value. The value of $y_{0 b}$ is the measured value of seismic motion intensity. The value of $\log U$ is approximately normally distributed, therefore the seismic motion intensity is also of logarithmic normal distribution.

\section{(3) Expected value of seismic motion intensity}

An expected value of seismic motion intensity is analyzed by a model of areal sources. The truncated G-R formula is used for evaluating the probability of exceeding a predetermined value defined as $y$ for a site having seismic motion intensity defined as $Y$, when earthquake occurs in $i$-th areal source $(i=1,2, \cdots$, $N)$. The probability is as follows; 


$$
P\left(Y>y \mid E_{i}\right)=1-\frac{\left.1-\exp \left[-\beta_{i} \mid g(y, r)-m_{0}\right\}\right]}{1-\exp \left[-\beta_{i} \mid m_{u i}-m_{0}\right\}}
$$

If the modified G-R formula is used, then the probability is as follows ;

$$
P\left(Y>y \mid E_{i}\right)=1-\frac{f(y)}{1-\exp \left\{-\beta_{i}\left(m_{u i}-m_{0}\right)\right\}-\beta_{i}\left(m_{u i}-m_{0}\right)}
$$

where $f(y)=1-\left[1-\beta_{i}\left|m_{u i}-g(y, r)\right|\right] \cdot \exp \left[-\beta_{i}\left|g(y, r)-m_{0}\right|\right]-\beta_{i}\left(m_{u i}-m_{0}\right)$,

$m=g(y, r)$, and $m_{u i}$ is the maximum magnitude for $i$-th areal source.

Defining the rate of the annual mean seismic occurrence, $\nu_{i}$ in $i$-th areal source, and the common origin of a circle with radius $r_{i}=r_{1 i} \sim r_{2 i}$, and angle $\theta_{i}=\theta_{1 i} \sim \theta_{2 i}$, then the frequency of occurrence $\lambda_{i}(y)$ for earthquakes in $i$-th areal source of $Y>y$ is as follows;

$$
\lambda_{i}(y)=\nu_{i} \cdot \theta_{i} \int_{r_{1 i}}^{r_{2 i}} P\left(Y>y \mid E_{i}\right) \cdot r d r
$$

The probability of $P\left(Y>y \mid E_{i}\right)$ in Eq. (9) is obtained either from Eq. (7) or Eq. (8). Further, if there are $N$ areal sources, then the frequency of occurrence $\lambda(y)$ at a site after taking consideration of all areal sources for $Y>y$ is as follows;

$$
\lambda(y)=\sum_{i=1}^{N} \nu_{i} \cdot \theta_{i} \int_{r_{1 i}}^{r_{2 i}} P\left(Y>y \mid E_{i}\right) \cdot r d r
$$

\section{(4) Poisson process}

The relation between $\lambda(y)$ and $y$ is based on seismic motion intensity of earthquakes observed. The Poisson process is adopted for inducing the probability of seismic occurrence ${ }^{\text {(l) }}$. The probability of $n$ times occurrences for seismic motion intensity $Y$ greater than $y$ within a duration $t$, is as follows,

$$
P(E)_{n}=\frac{\{\lambda(y) \cdot t\}^{n}}{n !} \cdot \exp \{-\lambda(y) \cdot t\}
$$

\section{DATA RELATED TO EARTHQUAKE AND ATTENUATION PROPERTY}

The straits of Akashi $\left(135^{\circ} 02^{\prime} \mathrm{E}, 34^{\circ} 36^{\prime} \mathrm{N}\right)$ was chosen as the site in this study. The following are the data are used.

\section{(1) Seismic data}

The seismic data were provided by references 12), 13), 14), 15) and 16). Accordingly the magnitudes for the period from 1885 to 1925,1926 to 1974 and 1975 to 1984 are taken to be, respectively, above 6. 0 , above 5. 5 , and above 5. 0 . The ratio of occurrence per unit area for magnitudes above 5 are grouped in the same range, as shown in Fig. 1. The maximum seismic magnitudes for the period of 416 and 1984 are shown in Table ${ }^{12}$.

\section{(2) Attenuation property}

The ground condition of the straits of Akashi is formed by rocky formation. The maximum seismic motion is expressed as follows ${ }^{9}$;

$$
A_{\max }=1073.0 \times 10^{0.221 \cdot m} \cdot(r+30)^{-1.251}
$$

and acceleration response spectra with damping factor of $5 \%$ is expressed as follows;

$$
S_{A}\left(T_{k}\right)=A\left(T_{k}\right) \times 10^{B\left(T_{k} \cdot m\right.} \cdot(r+30)^{a\left(T_{k}\right)}
$$

where $A\left(T_{k}\right), B\left(T_{k}\right)$, and $C\left(T_{k}\right)$ for various natural periods $T_{k}$ are shown in Table 2.

The dispersion index, $U$ with respect to maximum seismic motion and its response spectra are $\sigma_{\log } U_{A_{\max }}$ $\fallingdotseq 0.216$ and $\sigma_{\mathrm{log}} U_{s_{\Lambda}} \fallingdotseq 0.252$ respectively.

\section{INFLUENCE OF DECISION FACTOR OF SEISMIC LOAD FOR SHORT DURATION}

\section{(1) G-R formula}

The comparison between two formulae of G-R formulae was carried out. The value of $m_{u}$ are the maximum values that occured in the respective areal sources between the period of 416 and 1984 as shown in 


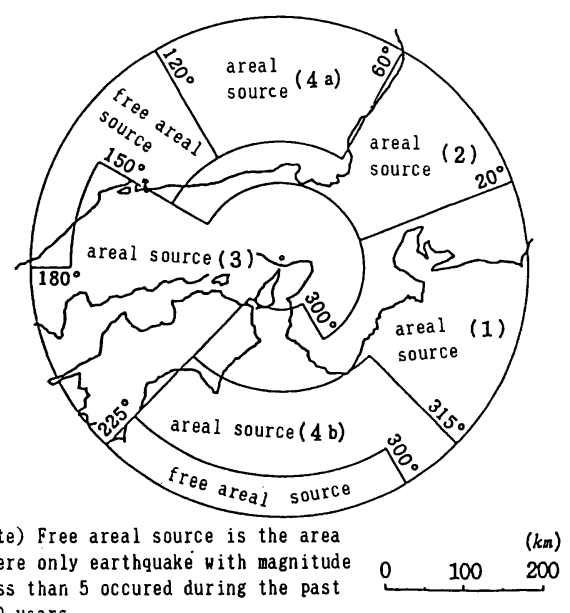

Table 1 Maximum magnitude for the period between 416 and 1984 .

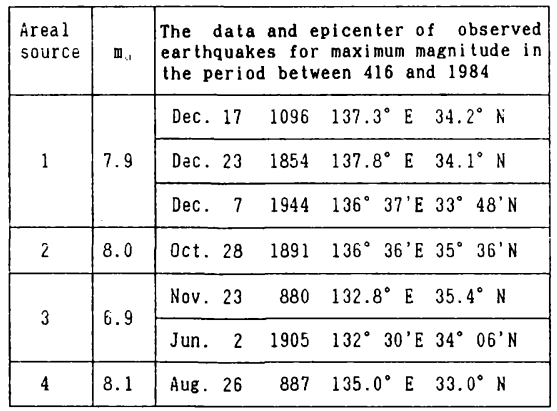
100 years.

Fig. 1 Areal sources model.

Table 1. The parameters $a$ and $b$ in G-R formulae are shown in Table 3. No significant difference was found out between the two formulae in the case of short duration. The truncated G-R formula, Eq. (2) is adopted in this analysis.

\section{(2) The minimum magnitude}

For specifying seismic load for the short duration, extrapolation of the G-R formula is required to predict the range of the magnitudes below 5. 0 . By taking the basic value as possible as smaller than 0.1 , the reduction ratio with respect to duration $t$ for $m_{0}=2.0,4.0$ and 5.0 is obtained as shown in Fig. 2. In this case, $m_{u}$ is the maximum magnitude in the period years between 416 and 1984 as shown in Table 1. It can be considered that the expected value of maximum seismic motion for one year becomes stable at the minimum magnitude, $m_{0}$ of 2.0 or less.

\section{(3) Conceivable maximum magnitude}

The conceivable maximum magnitude was estimated in the following three cases.

(a) The maximum value in the period between 416 and 1984, is used for the respective areal sources.

(b) The maximum value obtained from the seismic data in the period between 1885 and 1984 is used for the respective areal sources.

(c) The maximum value of 8.1 from reference 17), is used for the entire areal source.

Table 2 Parameter for attenuation formula (quoted from reference 9)).

\begin{tabular}{|c|c|c|c|}
\hline \multirow{2}{*}{$\begin{array}{l}\text { natural } \\
\text { period }\end{array}$} & \multicolumn{3}{|c|}{$\begin{array}{l}\text { parameter for at tenuation formula } \\
\text { of seismic response spectrum }\end{array}$} \\
\cline { 2 - 4 } & $\mathrm{A}(\mathrm{Tk})$ & $\mathrm{B}(\mathrm{Tk})$ & $\mathrm{C}(\mathrm{Tk})$ \\
\hline 0.1 & 2090 & 0.202 & -1.200 \\
\hline 0.15 & 2543 & 0.219 & -1.199 \\
\hline 0.2 & 1558 & 0.260 & -1.258 \\
\hline 0.3 & 1140 & 0.313 & -1.447 \\
\hline 0.5 & 111.0 & 0.261 & -0.9239 \\
\hline 0.7 & 60.24 & 0.286 & -0.9687 \\
\hline 1.0 & 57.69 & 0.366 & -1.321 \\
\hline 1.5 & 13.47 & 0.469 & -1.428 \\
\hline 2.0 & 10.77 & 0.454 & -1.422 \\
\hline 3.0 & 2.466 & 0.485 & -1.331 \\
\hline
\end{tabular}

Table 3 Parameter of Gutenberg-Richter formula.

\begin{tabular}{|c|c|c|c|c|c|c|}
\hline \multirow[t]{2}{*}{$\begin{array}{l}\text { areal } \\
\text { source }\end{array}$} & \multicolumn{3}{|c|}{$\begin{array}{l}\text { truncated Gutenberg- } \\
\text { Richter formula }\end{array}$} & \multicolumn{3}{|c|}{$\begin{array}{l}\text { modif ied Gutenberg- } \\
\text { Richter formula }\end{array}$} \\
\hline & a & b & $\mathbf{m}_{u}$ & a & b & $\mathbf{m}_{u}$ \\
\hline 1 & 5.01 & 0.854 & 7.9 & 3.31 & 0.612 & 7.9 \\
\hline 2 & 3.93 & 0.704 & 8.0 & 2.22 & 0.465 & 8.0 \\
\hline 3 & 4.15 & 0.774 & 6.9 & 1.72 & 0.352 & 6.9 \\
\hline 4 & 2.95 & 0.558 & 8.1 & 1.46 & 0.391 & 8.1 \\
\hline
\end{tabular}


The minimum magnitude, $M_{0}$ is taken as possible as smaller than 0.1 , when the maximum value from the record between 416 and 1984 is taken as the basic value. The ratio of increase for the other two cases are shown in Fig. 3. Thus, $M_{u}$ does not exert influence in the short period one years or less.

(4) Earthquake ground motion

The four conditions are used for evaluating the expected value of the ground motion intensity for an application period for short durations.

(a) The truncated G-R formula is used.

(b) The minimum magnitude, $M_{0}$ of 2.0 is used.

(c) The conceivable maximum magnitudes, $M_{u}$ are taken as the maximum value from the seismic catalogue in reference 12 ).

(d) The radious of the entire areal source is $300 \mathrm{~km}$.

The relation of $\lambda \sim S_{A}$ is shown in Fig. 4 and the expected value of acceleration response spectra in the respective divisions is shown in Fig. 5.

\section{NUMERICAL EXAMPLE}

\section{(1) Model of the installation of the bridge}

The numerical example is examined in the case of three span suspension bridge under construction. In the installation term of five years or more, the stiffened truss suffers from an earthquake during its installation period of one year eight months. The installation model assumes that there are five stages in the installation of the stiffened truss and each stage is four months long. Five major installation models are shown in Fig. 6.

The following are the assumption in the evaluation of the axial force of the stiffened truss that resulted from the earthquake effect as shown in Fig. 4 and 5.

(a) Assuming the inphase ground motion in the entire truss.

(b) Neglecting all loads except earthquake loads and dead loads.

(c) In the natural periods of 0.1 second or less and 3.0 seconds or more, the response spectra are extrapolated.

The axial resistant force of the stiffened truss chord and brace is determined by the yield strength of the material of each member. The mean value and standard deviation at the yield strength of the steel material is used.

(2) Probability of the failure

The probability of the failure of the chord, $P_{f, k, l, n}$ is given as follows;

$P_{f, k, l, n}=\sum_{j=1}^{N_{j}} P(E)_{j, k, n} \cdot P(F \mid E)_{j, k, l}$

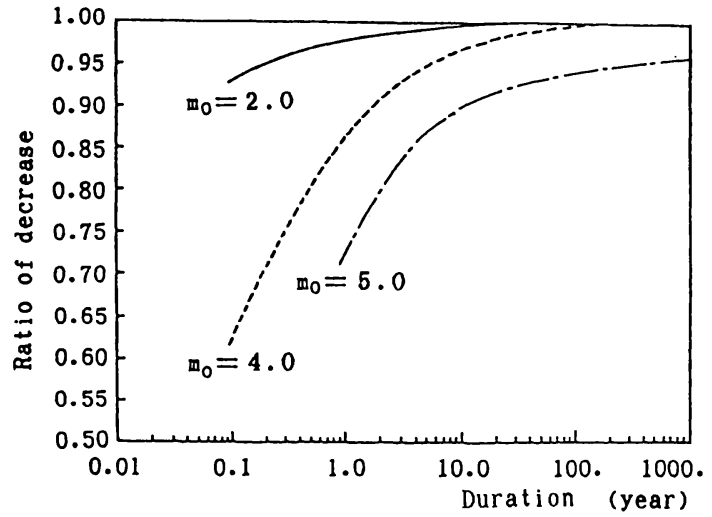

Fig. 2 Ratio of decrease expected value of maximum ground motion for variation in $M_{0}$.

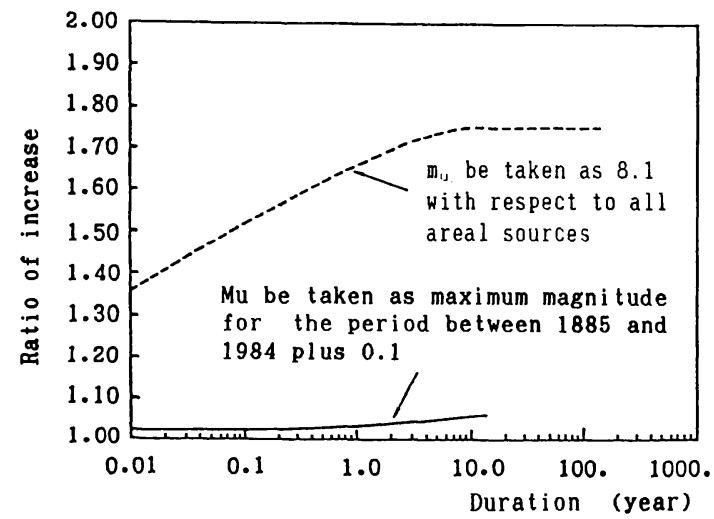

Fig. 3 Ratio of increase of expected value of maximum ground motion for variation in $M_{u}$ 


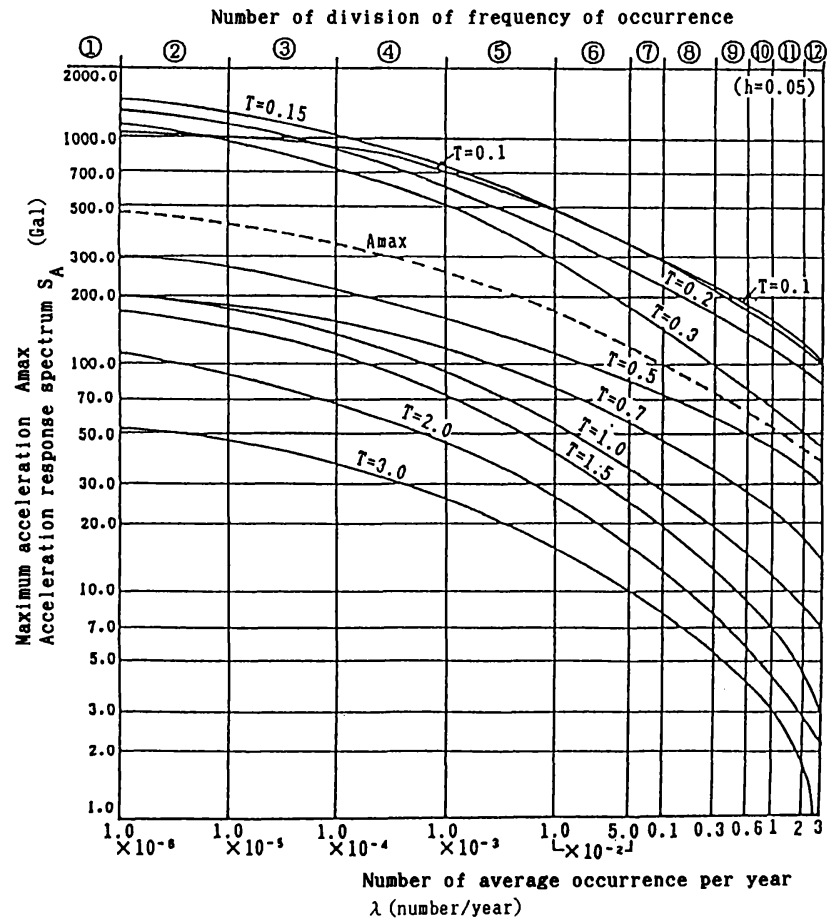

Fig. 4 Acceleration response spectrum for duration of 0.1 year to 1 year.

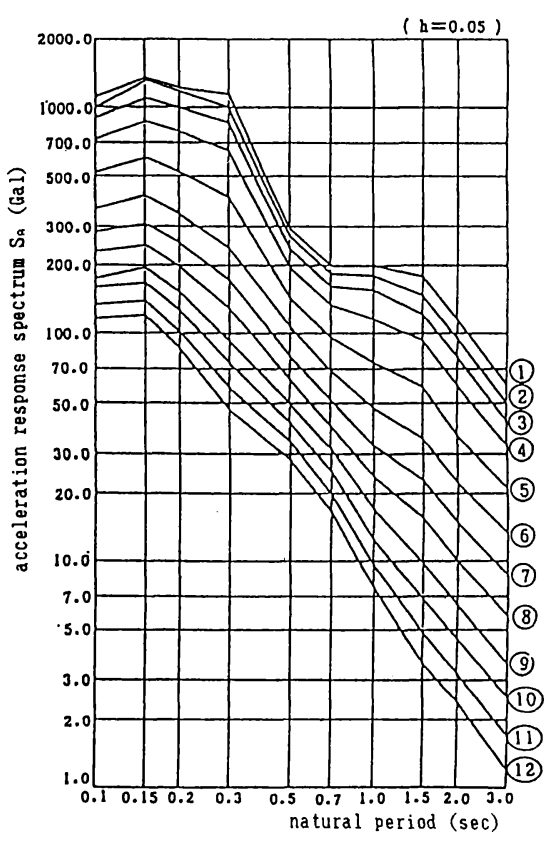

Fig. 5 Response spectrum curve for division of frequency of occurrence.

where

$P(E)_{j, k, n}$ : Probability of the failure of the $j$-th division of the frequency of the occurrence,

$N_{j}$ : Division number designated in Fig. 4 ,

$k:$ Sequence number of the stage of the installation period,

$l$ : Sequence number of the panel of the stiffened truss,

$n$ : Sequence number of the occurrence of the failure,

$j$ : Sequence number of the division of the frequency of the occurrence.

(3) Expected value of the restoration cost

In restoring the damaged portion of the truss as same as the original construction, the restoration

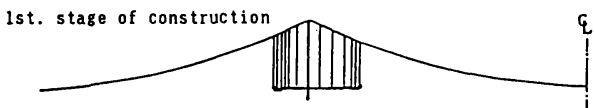

2nd. stage of construction

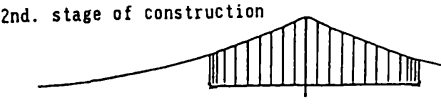

3rd. stage of construction

4th. stage of construction

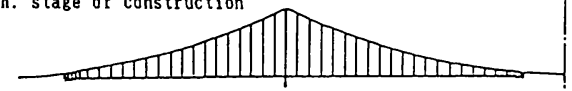

5th. stage of construction

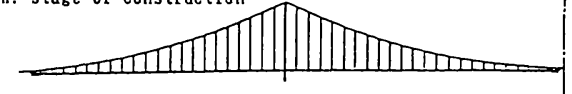

Fig. 6 Construction model of 3 -spans suspension bridge cost is assumed to be equal to the installation cost,

but the cost of the installation term longer than the original schedules is not taken into account.

The restoration cost $C_{k, l}$ is defined as follows;

$$
\bar{C}_{k, l}=\sum_{n=1}^{\infty} P_{f, k, l, n} \cdot r_{c, k, l} \cdot C_{u}
$$

where

$r_{c, k, l}:$ Reduction coefficient of the restoration cost, 
Table 4 Yield strength of steel member ${ }^{18)}$.

\begin{tabular}{|c|c|c|c|}
\hline steel grade & $\begin{array}{c}\text { wean value } \\
\bar{\sigma}_{Y}\left(\mathrm{MN} / \mathrm{Mn}^{\prime}\right)\end{array}$ & $\begin{array}{c}\text { standard } \\
\text { deviation } \\
\sigma_{\sigma_{Y}}\left(\mathrm{KN} / \mathrm{m}^{2}\right)\end{array}$ & $\begin{array}{c}\text { coefficient } \\
\text { of variation } \\
\delta_{R}(\%)\end{array}$ \\
\hline SS41 & 294. & 23.5 & 8. \\
\hline SH50Y & 373. & 29.4 & 8. \\
\hline SH58 & 431. & 25.5 & 6. \\
\hline HT70 & 667. & 27.5 & 4. \\
\hline
\end{tabular}

Table 5 Ratio of restoration cost.

\begin{tabular}{|l|c|}
\hline \multicolumn{1}{|c|}{$\begin{array}{l}\text { predeteruined } \\
\text { condition }\end{array}$} & $\begin{array}{l}\text { ratio of } \\
\text { restoration } \\
\text { cost } \\
R_{c}(\%)\end{array}$ \\
\hline $\begin{array}{l}\text { Reduction of } 50 \% \text { for 2nd. pane } 1 \\
\text { from tip of the installation, and } \\
\text { reduction of } 25 \% \text { for 3rd. and } \\
\text { 4th panel from tip of the } \\
\text { installation }\end{array}$ & 5.5 \\
\hline reduction is not considered & 7.5 \\
\hline
\end{tabular}

$C_{u}$ : Restoration cost of a unit panel when the failure occures in a completely installed stiffened truss.

The expected value of the total restoration cost of the stiffened truss, $\bar{C}$ is as follows;

$$
\bar{C}=\sum_{l=1}^{N_{l}} \sum_{k=1}^{N_{k}} \bar{C}_{k, l}
$$

where

$N_{k}$ : Total number of division of installation,

$N_{l}$ : Total number of panels.

The restoration cost ratio, $R_{c}$ of the restoration cost to the original construction cost is as follows ; $R_{c}=C / C_{0}$

where

$$
C_{0} \text { : Initial construction cost }\left(=N_{l} C_{u}\right) \text {. }
$$

Table 5 shows the expected value of failure frequency of the entire panels of the stiffened truss, and the restoration cost ratio. In this case, the total number of panel is 274 .

\section{CONCLUSION}

In this paper a probabilistic evaluation method for seismic loads in short durations and an example of its application are presented. The main results may be summarized as follows;

(1) The expected value of the maximum ground motion for short durations becomes stable at the minimum magnitude $M_{0}=2.0$ or less,

(2) The conceivable maximum magnitude for short durations has a small effect upon the value of ground motion intensity estimated by using either the maximum value from the recent seismic data in the period between 1885 and 1984 or the maximum value indicated by historical seismic data.

\section{ACKNOWLEDGEMENTS}

The authors sincerely express their appreciation to many persons who provided invaluable information and opinions. This study was supported in part by the Grant-in Aid for Scientific Research from the Ministry of Education, Science and Culture, Grant No. 58-46-0156 from 1983 to 1985 FY.

\section{REFERENCES}

1) JSCE : Earthquake Resistant Design for Civil Engineering Structures in Japan, 1980.

2) *Iwasaki, T, Kawashima, K. and Aizawa, K. : Predicting Method for the Expected Value of Seismic Motion Intensity Based on Past Seismic Activities, Technical report of PWRI, No. 1696, 1981.

3) *Ishikawa, Y, Okumura, T. and Ishii, K. : Factors that Affect the Probablistic Curve of Seismic Motion Based on the Historical Seismic Catalogues, Proc. 18th Earthquake Engineering, pp. 17 20, 1982.

4) Iwasaki, T., Kawashima, K. and Aizawa, K. : Effect of Subzoning in Estimating an Expected Intensity of Earthquake Ground Motion, Civil Engineering Journal, vol.24, No.2, Feb., pp. 15 20, 1982. 
5) Ishii, K. : The Seismic Risk of Structures Under Construction, Proc. JSCE, No. 281, pp. 11 16, 1979.

6) *Kuribayashi, E. and Iwasaki, T. : A Proposal on Seismic Load During Construction, The Bridge and Foundation Engineering, Vol. 7, No. 5, pp. 1 4, 1973.

7) Kumamoto, T., Ishii, K. and Hoshiya, M. : Probabilistic Evaluation of Design Alternative for Structures Under Construction, Proc. JSCE, No.385/VI-7, pp. 88 96, Sept. 1987.

8) Utsu, T. : Estimation of Parameters in Formulas for Frequency-Magnitude Relation of Earthquake Occurrence (In Cases In volving a Parameter $\mathrm{C}$ for the Maximum Magnitude), ZISIN, vol. 31, No. 2, pp. 367 382, 1987.

9) Kawashima, K. Aizawa, K and Takahashi, K. : Attenuation of Peak Ground Motion and Absolute Acceleration Response Spectra, Report of PWRI, Vol. 166, Sept. 1985.

10) Cornell, C. : Engineering Seismic Risk Analysis, BSSA, Vol. 58, No. 5, pp. 1583 1606, 1968.

11) Alfredo H-S. Ang Wilson H. Tang : Probability Concepts in Engineering Planning and Design, Vol. 1, Basic Principles, John Wiley \& sons, Inc., New York.

12) *Utsu, T. : The Seismic Activity of Japan (1885-1925), Bull. Earthq. Inst, Vol.54, pp. 253 308, 1979.

13) Japan Meteorological Agency : Catalogue of Relocated Major Earthquakes In And Near Japan (1926-1960), The Seismological Bulletin, Supplementary, Vol.6, 1982.

14) Japan Meteorological Agency : Catalogue of Relocated Major Earthquake In And Near Japan (1961-1962), The Seismological Bulletin, Supplementy, Vol.2, 1966.

15) Japan Meteorological Agency : Catalogue of Relocated Major Earthquake In And Near Japan (1963-1967), The Seismological Bulletin, Supplementary, Vol. 3, 1968.

16) Japan Meteorological Agency: The Seismological Bulletin (1968-1984)

17) Tokyo Astronomical Observation : Catalogue of Relocated Major Earthquakes In and Near Japan (1926-1960), Chronological Science Tables, pp. 780 808, 1985.

18) *Society of Steel Construction of Japan : Reliability and Safety of Steel Strucre, JSSC, Vol. 17, No. 179, pp. 17 53, 1981. (Note: Asterisk, *indicates the title literally translated from Japanese.)

(Received March 30 1987) 